\title{
Field Screening and Evaluation of Salt and Cold Tolerance of Wheat Germplasm Resources
}

\author{
X.P. LI ${ }^{1}$, S.Q. LAN ${ }^{1}$, Y.L. ZHANG ${ }^{1}$, L. LU ${ }^{2}$, S.E. LIU ${ }^{1}$, L.N. WANG ${ }^{1}$ and S. RAJARAM ${ }^{3}$ \\ ${ }^{1}$ Institute of Cereal and Oil Crops, Hebei Academy of Agricultural and Forestry Sciences, \\ Shijiazhuang 050031, P. R. China \\ ${ }^{2}$ Academy of Cangzhou Agricultural Sciences, Cangzhou, 061001, Hebei, P. R. China \\ ${ }^{3}$ International Center for Agricultural Research in the Dry Areas (ICARDA), P.O. Box 5466, Aleppo, \\ Syrian Arab Republic
}

(Received 24 March 2009; accepted 25 September 2009;

Communicated by J. Zhang)

\begin{abstract}
Abiotic stresses like salinity and abnormally cold environments cause significant yield losses in many crops including wheat. Therefore, concerted efforts are being made by breeders to develop new varieties with salt and cold tolerance to ensure stable yields over varied environments. This study was undertaken to screen six hundred and seventy-seven accessions of international wheat genetic resources to identify lines with high level of tolerance to salinity and cold environments. Based on the results of two years study in different agroecological locations, 51 accessions were classified as salt tolerant and 115 accessions were classified as cold tolerant. Of these, 35 accessions had good agronomic characteristics. Also, there were 39 genotypes with combined tolerance to cold as well as salinity. Thus, there were good lines which can be used directly or as parents for breeding wheat varieties for wide adaptation and high yield. Further analysis of the data showed that early genotypes had good cold tolerance but a poor salt tolerance. It was also observed that small number of both test spikelet and spikelet, short spike length and good seed-plump were positively associated with cold tolerance. Therefore, maturity and spike traits should be taken into considered when selecting wheat lines for wide adaptation breeding.
\end{abstract}

Keywords: bread wheat (Triticum aestivum), germplasm resources, abiotic stress, wheat breeding, cold tolerance, salt tolerance

\section{Introduction}

Bread wheat (Triticum aestivum) is a major food crop in the world. However, environmental stresses badly affect growth and development of wheat plants and cause severe reduction in yield. Salinity is a widespread problem in many countries. It reduces the ability of plants to take up water by lowering the soil water potential leading to internal water deficits (Munns 2002). Over six per cent of the world arable land is affected by salinity and near $100,000,000 \mathrm{hm}^{2}$ in China ( $\mathrm{Li}$ et al. 2005). To make the things worse, salinity of the soil caused by irrigation is increasing every year (Zeng and Wang 2005; Zhang 2005; Sun

* Corresponding author; E-mail: lixingpu@126.com 
et al. 2008). Desalinization of soil by drainage needs a large capital investment, a long time for relevant construction of the drainage system and it often results salinization the lower fields where the drainage water accumulates (Luo and Ren 2001). Therefore, breeding for salt tolerance by exploiting wheat genetic resources with high salt tolerance is the cheapest and best method to improve wheat yields and wide adaptability. Excessive cold is another important abiotic stress in northern China restricts the growth and development of wheat during the early- and mid-period growth stages of the winter wheat crop. Over the past decade, occurrence of severe cold spells have become more frequent and caused significant losses in wheat production (Wei et al. 2009). Therefore, breeding for cold and salt tolerant wheat varieties has become an urgent and major objective in the wheat improvement programs in China and other countries. A number of scientists have screened and developed many salt tolerance wheat materials (Farooq et al. 1995; Dong and Zheng 2000; El-Hendawy et al. 2005; Zhang 2005; Ma and Weng 2005; Munns et al. 2006; Timothy et al. 2006; Farooq et al. 2007; Sun et al. 2008; Mahmood and Baenziger 2008). However, a lack of high salt and cold tolerant germplasm resources with advanced comprehensive agronomic characteristics has affected the efficiency of breeding for resistance to abiotic stresses with high yield potential. This study reports the results of simultaneous screening and evaluation of a large number of international wheat germplasm lines for salt and cold tolerance at problem locations in China and lists promising genotypes with both advanced agronomic characteristics and stress tolerance which may be used for breeding programs.

\section{Materials and Methods}

\section{Materials and experimental sites}

Six hundred and seventy-seven accessions of international wheat genetic resources, which were collected mainly from 9 provinces of China and some from CIMMYT, were screened under salt and cold stress conditions at two different agro-ecological locations. Screening for salinity tolerance was conducted at the Institute of Cangzhou Agricultural Sciences, Cangzhou, China located in the region of salt stress. Screening for cold tolerance was conducted at the Institute of Tangshan Agricultural Sciences, Tangshan, China located in the region of sub-normal cold conditions. The lowest temperature is minus 30 ${ }^{\circ} \mathrm{C}$ in winter. All the materials also were planted at the Institute of Cereal and Oil Crops Hebei Academy of Agricultural and Forestry Sciences, Shijiazhuang with certain environmental characteristics of northern China for measuring their agronomic characteristics. After appraisal of cold and salt tolerance, the tolerance materials were used for second year's appraisal in the corresponding locations mentioned above. The data of cold and salt tolerance appraisal showed in this paper was from the second year.

Nitrogen fertilizer was applied at a rate of $38 \mathrm{~kg} \mathrm{ha}^{-1}$ and $103.5 \mathrm{~kg} \mathrm{ha}^{-1}$ just before sowing and the start of stem elongation, respectively. Phosphate fertilizer was applied at a rate of $103 \mathrm{~kg} \mathrm{ha}^{-1}$ just before stem elongation. Four-five times irrigations were conducted during the period of wheat plants development. Chemicals were applied to control aphids. 


\section{Agronomic characteristics test}

Each wheat germplasm line was sown in two row plots of $250 \mathrm{~cm}$ in length, $40 \mathrm{~cm}$ between rows, 250 grains for each row, and two replications with a randomized block design. Observations on different traits taken/scored using the method reported by Dong and Zheng (2000). Heading days was recorded as the number of days from emergence to heading (D_Head) and maturity was recorded as the number of days from emergence to maturing (D_Mat). Plant height (P_Height) was calculated as distance from the soil level to the tips of a random fistful of spikes, averaged across two replications per material. Twenty spikes from two replications of each accession were sampled to measure for spike length (Spike_L) and count for number of test_spikelet (N_Tspikelet) and spikelets (N_Spikelet) thousand-grain weight (TGW) was measured in grams by the average weight of two independent samples of 500 grains for each replication. Seed plump (S_Plump) was ranked in 5 grades and grade 1 means plump seeds.

\section{Screening for salinity tolerance}

Materials were sown in closed soil beds containing $0.41 \%$ salt. Each material was sown in a separate row of $150 \mathrm{~cm}$ in length ( $20 \mathrm{~cm}$ between rows, 150 grains for each row) with randomized design and two replications. The check 'Keyi 26' was sown once after every 7 accessions. Salt tolerance coefficient of the materials (yield of a material in salt bed/yield of neighbor check in salt bed), salt tolerance coefficient of the checks (yield of a check in salt bed/ the average yield of checks in salt bed) and salt tolerance index (salt tolerance coefficient of the material/salt tolerance coefficient of the neighbor check) were calculated after harvest. Salt tolerance index was indicated in 5 grades, and wheat genotypes ranked in grade 1 to grade 3 means salt-tolerance, and grade 4 to grade 5 means salt-sensitive (Zhao et al. 1995; Lu et al. 1996). Their corresponding relations were indicated as follows:

$\begin{array}{lccccc}\text { Grades of salt tolerance } & 1 & 2 & 3 & 4 & 5 \\ \text { Indexes of salt tolerance } & >1.3 & >1.1 & >0.8 & >0.5 & <0.5\end{array}$

Each material was compared with neighbor checks. If the materials were classified in lower salt tolerance grade than or equaled to check 'Keyi 26' (with salt tolerance grade 3), we call them salt tolerant genotypes.

\section{Screening for cold tolerance}

Each material was sown in two row plots of $250 \mathrm{~cm}$ in length $(40 \mathrm{~cm}$ between rows, 250 grains for each row) with randomized design. The check 'Dongfanghong 3' was sown once after every 50 accessions. After winter, wilting degree was scored in 5 scales as grades of cold tolerance (Dong and Zheng 2000). The seedlings leaves of the material without wilting was classified in salt tolerance grade 1 , and with leaf top wilting, half leaf wilting and whole leaf wilting was classified in grade 2, grade 3 and grade 4, respectively. Whole seedlings death was classified in grade 5 . The materials with equal or lower wilting degrees than the check (wilting degree of the check 'Dongfanghong 3' was grade 3) were regarded as cold resistant genotypes. 


\section{Statistic analysis}

Pearson's correlation coefficients between salt and cold stress and other agronomic traits were calculated, using PROC CORR in the Statistical Analysis System (SAS Institute, Cary, NC). Three hundred and fifty-four accessions were used for statistic analysis, and all the data used were from the first year.

\section{Results}

\section{Salinity tolerance evaluation}

Of the six hundred and seventy-seven accessions of wheat genetic resources screened, 20 accessions were classified in salt tolerant grade 1, and 16 accessions were classified in salt tolerant grade 2, and 15 were classified in salt tolerant grade 3 . Together these 51 lines were considered as salt tolerant (Tables 1-2). Among them there were 15 accessions with advanced comprehensive agronomic characteristics, such as An77-8 and Yan7770-4 with short plant, big spike and more grains per spike, Jihan 4589 with early maturity, short plant and high 1000-grain weight. Seven new lines (JI RS-1 JI RS-7) were tolerant to salt. In addition, during the experiment salt tolerance varied along with developmental stages was discovered. For example some have good tolerance at both seedling (with dark green color and without seedling or tiller death) and seeds filling stages (without leaf wilting and death), while others have different tolerant performance in seeds filling stage and seedling stage (data not shown).

\section{Cold resistance evaluation}

Seedling wilting degrees due to cold of 115 accessions were equal to that of the check Dongfanghong3 (wilting degree 3). Of these, there were 39 genotypes with tolerance to both cold and salinity (Table 2 ) and 20 accessions have advanced comprehensive agronomic characteristics. Fifteen wheat varieties released in the last 16 years were tolerant to cold as well as possessed good agronomic traits (Table 3).

\section{Relationship between salt and cold tolerance with other characters}

While seeking for the characters related to salt and cold tolerance, it was observed that there were significantly negative correlation between grade of salinity tolerance and both days from emerge to maturing $(p<0.01)$ and days from emerge to maturing $(p<0.05)$. It means that the ones with late maturity showed a better salt tolerance than the early ones. No other correlation was found between salinity tolerance and other characters. Interestingly, the genotypes with early maturity had a good cold tolerance but a bad salt tolerance (Table 4). Moreover, wilting degree of wheat seedlings had positive correlations with spike length, N_Spikelet, S_Plump as well as test spikelets $(\mathrm{p}<0.05)$. It showed that a small N_Tspikelet and N_Spikelet, short Spike and good Seed_Plump related to good cold tolerance. 
Table 1. Characteristics of 12 genotypes in salt tolerance grades 1 and 2

\begin{tabular}{|c|c|c|c|c|c|c|c|c|c|c|c|}
\hline Genotypes & $\begin{array}{c}\text { D-Head } \\
\text { (day) }\end{array}$ & $\begin{array}{l}\text { D-Mat } \\
\text { (day) }\end{array}$ & $\underset{(\mathrm{cm})}{\mathrm{P}_{\text {H Height }}}$ & $\begin{array}{c}\text { Spike_L } \\
\text { (cm) }\end{array}$ & N_Spikelet & N_Tspikelet & NGS & $\begin{array}{l}\text { TGW } \\
(\mathrm{g})\end{array}$ & S_Plump & Cold_G & Salt_G \\
\hline \multicolumn{11}{|l|}{ Keji26 } & 3 \\
\hline \multicolumn{12}{|l|}{ EM92hui } \\
\hline (ck2 sensitive) & 193 & 238 & 80 & 7.3 & 20.0 & 16.0 & 52.3 & 35.6 & 1 & 4 & 5 \\
\hline JI RS-6 & 202 & 245 & 84 & 8.9 & 18.0 & 17.7 & 35.0 & 40.0 & 2 & 4 & 1 \\
\hline JI RS-7 & 203 & 244 & 70 & 8.2 & 18.3 & 17.0 & 44.0 & 38.6 & 3 & 4 & 1 \\
\hline $7588 Y a$ & 203 & 243 & 78 & 8.2 & 19.3 & 18.0 & 59.3 & 33.4 & 2 & 4 & 1 \\
\hline An77-8 & 199 & 239 & 70 & 10.5 & 19.3 & 18.1 & 48.0 & 48.2 & 2 & 4 & 1 \\
\hline 78-024-30 & 197 & 244 & 55 & 7.5 & 19.0 & 17.8 & 50.7 & 36.6 & 3 & 5 & 1 \\
\hline Aimengniu & 202 & 245 & 65 & 8.8 & 20.0 & 18.9 & 58.3 & 39.0 & 3 & 4 & 1 \\
\hline Jingdong80-13 & 199 & 245 & 80 & 9.6 & 20.0 & 20.0 & 51.0 & 44.4 & 2 & 4 & 2 \\
\hline Yan7770-4 & 203 & 244 & 70 & 9.5 & 19.3 & 19.0 & 47.3 & 43.8 & 2 & 5 & 2 \\
\hline 79Dong79 & 203 & 241 & 75 & 9.0 & 18.0 & 17.7 & 51.0 & 36.2 & 3 & 4 & 2 \\
\hline DW-Zhuanyu-7 & 206 & 248 & 40 & 9.3 & 20.3 & 18.0 & 32.3 & 41.8 & 3 & 4 & 2 \\
\hline Xidedongmai & 200 & 245 & 82 & 8.3 & 17.0 & 16.2 & 42.7 & 50.8 & 2 & 4 & 2 \\
\hline 48130 & 207 & 246 & 78 & 11.7 & 19.0 & 18.0 & 51.7 & 28.8 & 5 & 4 & 2 \\
\hline
\end{tabular}

Notes: Salt_G = grade of salinity tolerance; Cold_G = wilting degree of seedling after winter; D_Head = days from emerge to heading; D_Mat = days from emerge to maturity; P Height = plant height; Spike L = spike length; N Spikelet $=$ number of spikelet per spike; N_Tspikelet $=$ number of test spikelet per spike; NGS = number of grains per spike; TGW = 1000-grain weight; S_Plump = plump of seed. 
Table 2. Characteristics of 39 genotypes tolerance to both salt and cold stresses

\begin{tabular}{|c|c|c|c|c|c|c|c|c|c|c|c|}
\hline Genotypes & $\begin{array}{l}\text { D-Head } \\
\text { (day) }\end{array}$ & $\begin{array}{l}\text { D-Mat } \\
\text { (day) }\end{array}$ & $\begin{array}{c}\text { P_Height } \\
(\mathrm{cm})\end{array}$ & $\begin{array}{l}\text { Spike_L } \\
(\mathrm{cm})\end{array}$ & N_Spikelet & N_Tspikelet & NGS & $\begin{array}{l}\mathrm{TGW} \\
(\mathrm{g})\end{array}$ & S_Plump & Cold_G & Salt_G \\
\hline $\begin{array}{l}\text { Dongfanghong3 } \\
\text { (CK cold tolerance) }\end{array}$ & 202 & 240 & 105 & 9.8 & 20.0 & 19.7 & 49.7 & 42.0 & 2 & 3 & 5 \\
\hline Keji26 & & & & & & & & & & & \\
\hline (ck1 salt tolerance) & 202 & 246 & 135 & 9.3 & 17.0 & 15.8 & 42.0 & 33.2 & 3 & 4- & 3 \\
\hline JI RS-1 & 200 & 243 & 76 & 9.8 & 17.3 & 16.0 & 42.0 & 30.7 & 1 & 3 & 1 \\
\hline JI RS-2 & 202 & 246 & 79 & 8.0 & 14.3 & 13.3 & 52.0 & 32.7 & 1 & 3 & 1 \\
\hline JI RS-3 & 201 & 244 & 83 & 6.5 & 16.3 & 15.6 & 44.0 & 36.4 & 1 & 3 & 1 \\
\hline JI RS-4 & 202 & 244 & 80 & 9.2 & 17.3 & 16.3 & 36.0 & 38.9 & 1 & 3 & 1 \\
\hline JI RS-5 & 203 & 246 & 78 & 8.9 & 18.0 & 18.0 & 41.0 & 39.5 & 1 & 3 & 1 \\
\hline Jihan 4589 & 201 & 240 & 75 & 6.4 & 17.0 & 14.6 & 33.4 & 40.8 & 2 & 3 & 2 \\
\hline Baiquan84-3129 & 199 & 239 & 58 & 8.5 & 20.3 & 19.3 & 45.7 & 39.0 & 3 & 3 & 1 \\
\hline Jiza C221 & 204 & 242 & 65 & 6.2 & 16.3 & 15.6 & 37.0 & 32.2 & 3 & 3 & 1 \\
\hline 8003 & 210 & 239 & 80 & 7.8 & 20.3 & 18.3 & 51.3 & 40.4 & 1 & 3 & 1 \\
\hline $890 \mathrm{C} 2-2311$ & 204 & 245 & 77 & 11.7 & 21.3 & 19.0 & 45.3 & 34.4 & 3 & 3 & 1 \\
\hline $82-6110$ & 200 & 239 & 80 & 8.0 & 17.0 & 15.0 & 38.7 & 33.8 & 1 & 3 & 1 \\
\hline Linfen 605 & 199 & 242 & 75 & 5.1 & 15.5 & 14.7 & 31.7 & 43.8 & 1 & 3 & 1 \\
\hline Lainong8543 & 200 & 240 & 75 & 8.6 & 18.7 & 17.9 & 59.7 & 35.4 & 2 & 3 & 1 \\
\hline 836361 & 199 & 244 & 80 & 8.3 & 18.3 & 16.0 & 55.0 & 41.0 & 2 & 3 & 1 \\
\hline
\end{tabular}


Table 2 (cont.)

\begin{tabular}{|c|c|c|c|c|c|c|c|c|c|c|c|}
\hline Genotypes & $\begin{array}{l}\text { D-Head } \\
\text { (day) }\end{array}$ & $\begin{array}{l}\text { D-Mat } \\
\text { (day) }\end{array}$ & $\begin{array}{c}\text { P_Height } \\
(\mathrm{cm})\end{array}$ & $\begin{array}{c}\text { Spike_L } \\
(\mathrm{cm})\end{array}$ & N_Spikelet & N_Tspikelet & NGS & $\begin{array}{c}\text { TGW } \\
\text { (g) }\end{array}$ & S_Plump & Cold_G & Salt_G \\
\hline Ji83-4169 & 201 & 238 & 83 & 11.7 & 22.0 & 19.8 & 36.7 & 34.2 & 3 & 3 & 1 \\
\hline 78154-4 & 203 & 240 & 65 & 7.2 & 20.0 & 20.0 & 60.0 & 28.7 & 4 & 3 & 2 \\
\hline Linfen84-525 & 199 & 238 & 67 & 8.3 & 18.0 & 16.7 & 51.7 & 38.6 & 1 & 3 & 2 \\
\hline $79(50)-34-1-2$ & 200 & 240 & 80 & 7.5 & 16.3 & 16.3 & 48.7 & 49.2 & 2 & 3 & 2 \\
\hline $79001-1-1$ & 199 & 239 & 80 & 9.3 & 19.7 & 17.0 & 37.0 & 43.4 & 1 & 3 & 2 \\
\hline $80-22$ & 200 & 238 & 65 & 7.2 & 19.3 & 19.0 & 51.3 & 41.4 & 2 & 3 & 2 \\
\hline $80(128)-20-6$ & 203 & 245 & 72 & 8.7 & 20.0 & 19.7 & 60.7 & 45.4 & 2 & 3 & 2 \\
\hline Linfen85-517 & 199 & 241 & 80 & 9.9 & 19.3 & 18.2 & 49.0 & 42.8 & 2 & 3 & 2 \\
\hline Rc4 & 201 & 241 & 80 & 7.8 & 17.3 & 16.1 & 69.7 & 39.8 & 2 & 3 & 2 \\
\hline $86-2580$ & 200 & 238 & 77 & 9.2 & 18.3 & 17.7 & 48.0 & 37.0 & 3 & 3 & 2 \\
\hline CA8056 & 202 & 239 & 80 & 7.9 & 17.0 & 16.0 & 34.3 & 25.4 & 3 & 3 & 3 \\
\hline 7410017-9-13 & 203 & 242 & 70 & 8.3 & 18.0 & 18.0 & 40.7 & 41.0 & 2 & 3 & 3 \\
\hline 7588Sui-1/3-18-1-1 & 203 & 243 & 75 & 8.3 & 18.4 & 18.4 & 50.7 & 35.2 & 3 & 3 & 3 \\
\hline $80(4) 055$ & 203 & 243 & 73 & 7.5 & 19.3 & 18.0 & 38.7 & 43.8 & 2 & 3 & 3 \\
\hline Linfen 51379 & 199 & 238 & 75 & 8.3 & 18.3 & 16.3 & 51.3 & 37.4 & 2 & 3 & 3 \\
\hline 1D13-121 & 206 & 244 & 70 & 9.2 & 20.7 & 20.0 & 58.0 & 25.4 & 5 & 3 & 3 \\
\hline 110013 & 203 & 244 & 65 & 7.7 & 18.3 & 18.0 & 43.0 & 46.0 & 2 & 3 & 3 \\
\hline $7770-224-2$ & 203 & 244 & 70 & 8.2 & 20.3 & 19.6 & 52.0 & 40.4 & 2 & 3 & 3 \\
\hline $78380-2-3-4$ & 203 & 243 & 78 & 8.7 & 19.7 & 18.7 & 63.7 & 33.5 & 2 & 3 & 3 \\
\hline Dongxie no.2 & 200 & 242 & 80 & 8.0 & 19.0 & 18.0 & 43.7 & 34.2 & 2 & 3 & 3 \\
\hline Baiquan 3039 & 199 & 240 & 70 & 7.7 & 17.0 & 16.3 & 51.0 & 34.4 & 2 & 3 & 3 \\
\hline $84-6085$ & 201 & 241 & 80 & 7.6 & 17.3 & 16.9 & 42.6 & 34.8 & 2 & 3 & 3 \\
\hline $7730-6$ & 197 & 240 & 80 & 8.5 & 18.7 & 18.0 & 46.7 & 34.2 & 2 & 3 & 3 \\
\hline Tai 5Xinxuan 308 & 198 & 242 & 80 & 9.1 & 17.3 & 16.6 & 47.0 & 46.2 & 2 & 3 & 3 \\
\hline 814527 & 202 & 238 & 80 & 9.7 & 20.0 & 18.7 & 56.0 & 35.2 & 2 & 3 & 3 \\
\hline
\end{tabular}

Notes: For abbreviations see footnote Table 1 
Table 3. Characteristics of 15 released wheat varieties tolerance to cold stress

\begin{tabular}{|c|c|c|c|c|c|c|c|c|c|c|}
\hline Genotypes & $\begin{array}{c}\text { D-Head } \\
\text { (day) }\end{array}$ & $\begin{array}{c}\text { D-Mat } \\
\text { (day) }\end{array}$ & $\begin{array}{c}\text { P_Height } \\
(\mathrm{cm})\end{array}$ & $\begin{array}{c}\text { Spike_L } \\
(\mathrm{cm})\end{array}$ & N_Spikelet & N_Tspikelet & NGS & $\begin{array}{c}\text { TGW } \\
\text { (g) }\end{array}$ & S_Plump & Cold_G \\
\hline \multicolumn{11}{|l|}{ Dongfanghong3 } \\
\hline (CK cold tolerance ) & 202 & 240 & 105 & 9.8 & 20.0 & 19.7 & 49.7 & 42.0 & 2 & 3 \\
\hline Baiyingdong 2 & 201 & 240 & 66 & 7.5 & 18.0 & 15.2 & 43.2 & 42.0 & 1 & $3+$ \\
\hline Han 5316 & 201 & 240 & 80 & 8.0 & 17.0 & 14.4 & 34.6 & 41.9 & 1 & 3 \\
\hline Han 6172 & 201 & 238 & 75 & 7.4 & 17.0 & 14.8 & 36.2 & 42.8 & 1 & $3+$ \\
\hline Hanmai 9 & 201 & 235 & 77 & 8.3 & 17.0 & 15.2 & 41.8 & 45.8 & 2 & $3+$ \\
\hline Hanyou 3475 & 200 & 240 & 80 & 7.0 & 15.0 & 13.0 & 36.2 & 42.2 & 1 & 3 \\
\hline Henong 326 & 198 & 242 & 75 & 7.4 & 17.0 & 13.4 & 33.6 & 43.4 & 1 & 3 \\
\hline Heng 4041 & 202 & 245 & 70 & 8.2 & 14.0 & 13.2 & 33.0 & 36.0 & 2 & 3 \\
\hline Hua 521 & 200 & 242 & 82 & 7.3 & 16.0 & 14.0 & 31.8 & 41.6 & 2 & 3 \\
\hline Ji 5385 & 198 & 239 & 75 & 8.6 & 15.0 & 13.0 & 30.6 & 46.0 & 1 & $3+$ \\
\hline Jimai 34 & 202 & 249 & 90 & 7.5 & 16.0 & 12.8 & 28.0 & 39.0 & 1 & 3 \\
\hline Shijiazhuang 8 & 200 & 237 & 75 & 7.8 & 16.0 & 12.4 & 34.0 & 43.1 & 1 & 3 \\
\hline Shixin 733 & 199 & 240 & 75 & 7.0 & 15.0 & 12.8 & 35.4 & 43.8 & 1 & 3 \\
\hline Jimai 36 & 199 & 248 & 80 & 8.0 & 16.0 & 14.4 & 32.0 & 36.0 & 2 & 3 \\
\hline Zhongmai 9 & 202 & 248 & 80 & 7.8 & 15.0 & 12.8 & 28.2 & 46.2 & 2 & 2 \\
\hline Zhongyou 9507 & 201 & 249 & 90 & 8.7 & 17.0 & 15.4 & 26.2 & 46.2 & 2 & 2 \\
\hline \multicolumn{11}{|c|}{ Notes: For abbreviations see footnote Table 1.} \\
\hline \multicolumn{11}{|c|}{ Table 4. Correlations between abiotic resistance and other agronomic characteristics } \\
\hline Genotypes & $\begin{array}{c}\text { D-Head } \\
\text { (day) }\end{array}$ & $\begin{array}{l}\text { D-Mat } \\
\text { (day) }\end{array}$ & $\begin{array}{l}\text { P_Height } \\
(\mathrm{cm})\end{array}$ & $\begin{array}{c}\text { Spike_L } \\
(\mathrm{cm})\end{array}$ & N_Spikelet & N_Tspikelet & NGS & & $\begin{array}{l}\text { TGW } \\
(\mathrm{g})\end{array}$ & S_Plump \\
\hline Cold G & $0.105^{*}$ & $0.106^{*}$ & -0.102 & $0.105^{*}$ & $0.121 *$ & $0.128^{*}$ & 0.025 & & 0.103 & $0.106^{*}$ \\
\hline Salt G & $-0.105^{*}$ & $-0.151 * *$ & -0.004 & 0.051 & -0.037 & -0.073 & -0.051 & & -0.039 & -0.048 \\
\hline
\end{tabular}




\section{Discussion}

\section{Salt tolerance}

Statistics analysis showed that salt tolerance was significantly associate with the D-Head and D-Mat of the genotypes (Table 4) indicating that lines with earlier heading and maturity might be more susceptible to salinity. Previous reports have also indicated that heading date of wheat has a large effect on stress tolerance of wheat (Ma and Weng 2005; Song et al. 2006).

Furthermore, the late maturing cultivars commonly exist in north of China in arid and semi-arid region (Wang 1993; Cao and Wu 2000), where plants must have a higher relatively salt-tolerance for surviving on the condition of alkaline soils than that in south of China. Therefore, natural and artificial selections might make the late-maturity-characteristics of crops and salt tolerance together, and Cattivelli et al. (2002) provided a molecular evidence for their relationship that a high concentration of quantitative trait loci (QTLs) on group 5 chromosomes which mainly control heading date, cold and salt tolerance. So, these QTLs might be either one gene or different ones but adjacent to each other. If they were one, this gene may represent the molecular basis of stress tolerance, or different ones, the adjacency to each other on chromosome may result in linkage disequilibrium which makes them present together at a higher ratio than other genotypes. Therefore, these suggested that the wheat genotypes with high salt-tolerance should be characterized by late maturity.

\section{Cold tolerance}

Unlike the characters of salt tolerance, early heading and maturity cultivars had good cold tolerance (Table 4). From the point of evolution, heading date is directly associated with adaptation of plants (Allard and Jain 1962). Generally, early development of genotype is not viewed as a good character for cold tolerance, which would result in freezing injury in early spring. However, this was broken in West Asia and North Africa, and early heading cultivars with winter hardiness and tiller frost avoidance are required for ensuring a long enough grain filling process and an effective utilization of the limited soil water prior to high temperature in early summer (Austin, 1982; Fujita et al. 1992). Interestingly, these regions and the north of China have homologous circumstances, and therefore, leading to similar characters of cultivars in these regions. Early heading date and shorten growth period might be the result of adaptation to ecological surroundings of these regions, avoiding dry-hot wind during later seed filling period, so beneficial to good S_plump and TGW. However, this rapid development process also lead to short Spike_L, small N_spikelet, and N_Tspikelet.

\section{Methods for evaluating tolerance to abiotic stresses}

Many ways to identify salt and cold tolerance genotypes has been reported (Quamme 1982; Kingsbury and Emanuel 1984; Ashraf and McNeilly 1988; Munns et al. 1995; Royo et al. 2000; Steppuhn et al. 2005). The ratio of leaf death over the total leaves was clearly 
greater on the sensitive genotypes than the tolerant ones (Munns et al. 1995). The rate of leakage of electrolytes from plant tissues after a freezing stress was indicated as a potential criterion for freezing tolerance (Quamme1982). Physiological characters that underlie traits for salt tolerance could be used to identify new genetic resources of salt tolerance (Munns et al. 2006). Salt tolerance was associated with low rates of transport of $\mathrm{Na}^{+}$to shoots and high selectivity for $\mathrm{K}^{+}$(Gorham et al. 1990). Despite those physiological characteristics linked to cold or salt tolerance trait, the best selection criteria should be the rate of winter survival or seedling wilting grade after freezing, and grades of salt tolerance for breeding practice because they were easy, inexpensive, accurate and rapid method for screening large germplasm resources. Also, grades of salt tolerance which was used in this experience were calculated according to the grain yield. It is more useful for high yield and adaptation breeding.

\section{Acknowledgements}

The authors are grateful to Mr. Bai Yulong and Yuqin Li for the help in tolerance evaluation and grateful to Dr. Gongshe Hu and Dr. B.B. Singh for modifying the paper. This work was supported by both National science and technology underpinning Project of China (2006BAD13B02-08), and by Hebei Provencal science and technology underpinning project (20071148001).

\section{References}

Ashraf, M., McNeilly, T. 1988. Variability in salt tolerance of nine spring wheat cultivars. J. Agron. and Crop Sci. 160:14-21.

Allard, R.W., Jain, S.K. 1962. Population studies in predominantly self-pollinated species, II. Analysis of quantitative changes in a bulk hybrid population of barley. Evolution 16:90-101.

Austin, R.B. 1982. Crop characteristics and potential yield of wheat. J. Agric. Sci. Camb. 98:447-453.

Cao, G.C., Wu, D.B. 2000. Geographical changes of the growth duration of common wheat and its different varietal ecotypes. Agric. Meteorol. 21:29-32.

Cattivelli, L., Baldi, P., Crosatti, C., Fonzo, N.D., Faccioli, P., Grossi, M., Mastrangelo, A.M., Pecchioni, N., Stanca, A.M. 2002. Chromosome regions and stress-related sequences involved in resistance to abiotic stress in Triticeae. Plant Mol. Biol. 48:649-665.

Dong, Y.C., Zheng, D.S. 2000. Chinese Wheat Genetic Resources. China Agricultural Press, Beijing. pp. 4-5.

El-Hendawy, S.E., Hu, Y.C., Yakout, G.M., Awad A.M., Hafiz, S.E., Schmidhalter, U. 2005. Evaluating salt tolerance of wheat genotypes using multiple parameters. Europ. J. Agron. 22:243-253.

Farooq, S., Azam, F. 2007. Differences in behavior of salt tolerant and salt and water deficiency tolerant wheat genotypes when subjected to various salinity levels. Cereal Res. Commun. 35:63-70.

Farooq, S., Asghar, M., Iqbal, N., Askari, E., Arif, M., Shah, T.M. 1995. Production and evaluation of salt tolerant wheat germplasm produced through crossing wheat (Triticum aestivum L.) with Aegilops cylindrica-II. Field evaluation of salt tolerant germplasm. Cereal Res. Commun. 23:275-282.

Fujita, M., Kawada, N., Tahir, M. 1992. Relationship between cold resistance, heading traits and ear primordial development of wheat cultivars. Euphytica 64:123-130.

Gorham, J., Wyn Jones, R.G., Bristol, A. 1990. Partial characterization of the trait for enhanced $\mathrm{K}^{+}-\mathrm{Na}^{+}$discrimination in the D genome of wheat. Planta 180:590-597.

Kingsbury, R.W., Emanuel, E. 1984. Selection for salt-resistant spring wheat. Crop Sci. 24:310-315.

Li, B., Wang, Z.C., Sun, Z.G., Chen, Y., Yang, F. 2005. Resources and sustainable resource exploitation of salinized land in China. Agric. Res. Arid Areas 23:154-158.

Cereal Research Communications 38, 2010 
Lu, L., Zhang, H.Y., Li, G.R. 1996. Wheat salt-tolerant mutant RS8901-17. Breeds Res. Crop 1:55.

Luo, T.B., Ren, W. 2001. Effect on planting salt-tolerant wheat to salinized fields in Xin jiang. Chinese J. Eco-Agric. 9:102-103.

Ma, Y.Q., Weng, Y.J. 2005. Evaluation for salt tolerance in spring wheat cultivars introduced from abroad. Acta Agron. Sin. 31:58-64.

Mahmood, A., Baenziger, P.S. 2008. Creation of salt tolerant wheat doubled haploid lines from wheat $\times$ maize crosses. Cereal Res. Commun. 36:361-371.

Munns, R. 2002. Comparative physiology of salt and water stress. Plant Cell Environ. 25:239-250.

Munns, R., Schachtman, D.P., Condon, A.G. 1995. The significance of a two-phase growth response to salinity in wheat and barley. Australian J. Plant Physiol. 22:561-569.

Munns, R., James, R.A., Läuchli, A. 2006. Approaches to increasing the salt tolerance of wheat and other cereals. J. Exp. Botany 57:1025-1043.

Quamme, H.A. 1982. Breeding and selecting temperate food crops for cold hardiness. In: Li, P.H., Sakai, A. (eds.), Plant Cold Hardiness and Freezing Stress Mechanism and Crop Implications. Academic Press, New York, USA, $313 \mathrm{pp}$.

Royo, A., Aragüés, R., Playán, E., Ortiz, R. 2000. Salinity-grain yield response functions of barley cultivars assessed with a drip-injection irrigation system. Soil Sci. Society of America J. 64:359-365.

Song, Y.X., Jing, R.L., Huo, N.X., Ren, Z.L., Jia, J.Z. 2006. Detection of QTLs for heading in common wheat (T. aestivum L.) using different populations. Sci. Agric. Sin. 39:2186-2193.

Steppuhn, H., Genuchten, M.T., Grieve, C.M. 2005. Root-zone salinity. I. Selecting a product-yield index and response functions for crop tolerance. Crop Sci. 45:209-220.

Sun, J.C., Wang, X.S., Yang, S.L. 2008. Progress of research on salt-resistance in plants. Agric. Res. Arid Areas 26:226-230.

Timothy, D., Timothy, C., Flowers J., Munns, R. 2006. Use of wild relatives to improve salt tolerance in wheat. J. Exp. Botany 57:1059-1078.

Wang, Z.Q. 1993. Salt-affected Soils in China. Beijing, Science Press. 63 pp.

Wei, X.Y., Ou, X.Q., Li, X.H., Tang, J.X. 2009. Change of physiological characteristics of different wheat varieties under the low temperature in winter and spring in Huanghuai area. Hubei Agric. Sci. 48:47-50.

Zeng, H.X., Wang, J. 2005. The salt injury physiology and salt resistance of plant. Bull. Biol. 40:1-3.

Zhang, X.P. 2005. Study on salt-resistance of wheat varieties in saline-alkaliareas in Baiyin city of Gansu province. Agric. Res. in the Arid Areas 23:103-107.

Zhao, R.T., Gao, S.G. 1995. Studies on the application of anther culture in salt tolerance breeding in wheat (Triticum aestivum L.). Acta Agron. Sin. 21:230-234.

Cereal Research Communications 38, 2010 